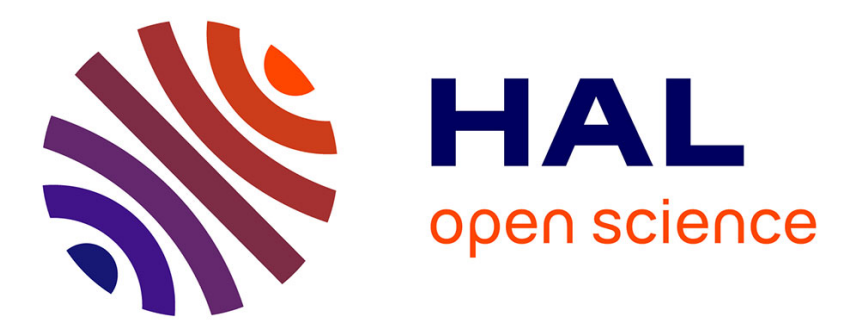

\title{
In Situ Kinetics Study of the Accelerated Aging of Poly(ethylene oxide) Using PhotoDSC
}

Frédéric Fraisse, Sandrine Morlat-Therias, Jean-Luc Gardette, Jean-Marie

Nedelec, Mohamed Baba

\section{- To cite this version:}

Frédéric Fraisse, Sandrine Morlat-Therias, Jean-Luc Gardette, Jean-Marie Nedelec, Mohamed Baba. In Situ Kinetics Study of the Accelerated Aging of Poly(ethylene oxide) Using PhotoDSC. Journal of Physical Chemistry B, 2006, 110 (30), pp.14678-14684. 10.1021/jp061669g • hal-00154707

\section{HAL Id: hal-00154707 https://hal.science/hal-00154707}

Submitted on 14 Jun 2007

HAL is a multi-disciplinary open access archive for the deposit and dissemination of scientific research documents, whether they are published or not. The documents may come from teaching and research institutions in France or abroad, or from public or private research centers.
L'archive ouverte pluridisciplinaire HAL, est destinée au dépôt et à la diffusion de documents scientifiques de niveau recherche, publiés ou non, émanant des établissements d'enseignement et de recherche français ou étrangers, des laboratoires publics ou privés. 


\title{
In situ kinetics study of the accelerated ageing of poly(ethylene oxide) by photoDSC
}

\author{
F. Fraisse ${ }^{1}$, S. Morlat-Thérias ${ }^{1}$, J-L. Gardette ${ }^{1}$, J-M. Nedelec ${ }^{2}$ and M. Baba ${ }^{* 1}$ \\ ${ }^{1}$ Laboratoire de Photochimie Moléculaire et Macromoléculaire, UMR CNRS 6505 \\ ${ }^{2}$ Laboratoire des Matériaux Inorganiques, UMR CNRS 6002
}

Ecole Nationale Supérieure de Chimie de Clermont-Ferrand et Université Blaise Pascal, 24 Av. des Landais, 63174 Aubière Cedex, France.

\begin{abstract}
PhotoDSC has been applied to follow the global kinetics of chain scissions resulting from the UV light irradiation or from the thermal degradation of a high molecular weight PEO $\left(4 \times 10^{6}\right.$ g.mol $\left.{ }^{-1}\right)$. Infrared spectroscopy, XRD measurements and rheology experiments were performed to evidence the occurrence of chain scissions... Melting energy was used as a tool to quantify the extent of the degradation. It was found that the chain scissions reaction follows a first order kinetic law for both photo and thermal degradation. The activation energies were found identical in both cases $\left(41 \mathrm{~kJ}^{-\mathrm{mol}^{-1}}\right)$ whereas the degradation rate was higher in the case of UV irradiation than in the case of thermoageing
\end{abstract}

Key words : PhotoDSC, in situ ageing, polymers, PEO 


\section{Introduction}

PhotoDSC combines in a single equipment light irradiation and DSC measurement. Light is brought inside the DSC furnace by two symmetrical optical fibers. Classically, photoDSC is devoted to photopolymerisation studies. The heat released by the light/matter interactions is directly recorded by the DSC apparatus. In a previous paper [1] we demonstrated that the photoDSC system can be considered as a very useful and versatile device for the in situ study of ageing of semicrystalline polymers. In fact, the possibility of easily controlling the temperature $\left(-150\right.$ to $\left.500{ }^{\circ} \mathrm{C}\right)$, the nature of the atmosphere $\left(\mathrm{O}_{2}, \mathrm{~N}_{2}\right.$, air ...), the irradiation power $(0-2000 \mathrm{~mW})$ and the irradiation wavelength make this device an efficient tool to perform and characterize artificial accelerated photo and thermo degradation.

This paper presents a kinetic study of thermo and photoageing of poly(ethylene oxide), PEO, at several temperatures and light intensities. PEO is a semicrystalline water-soluble polymer [2,3], with a crystallinity that is very sensitive to the thermal history of the samples $[4,5,6]$, which makes this property interesting as an indicator of the degradation.

Because it is a biodegradable and biocompatible polymer, PEO is a good candidate for environmental and medical applications [7,8]. The mechanisms of thermo and photooxidation of PEO have already been investigated $[9,10]$ on the basis of IR identifications of the oxidation products. Interestingly it was found that photooxidation favors the accumulation of formates against esters whereas thermooxidation leads to equal amounts of both these oxidation products. It can be anticipated that both these conditions of ageing result in different modifications of the macromolecular architecture since the formation of formats is accompanied by macromolecular chain scissions and not that of esters.

The aim of this study is to show how photoDSC can be used to obtain kinetics constants and determine the thermodynamics properties associated to the degradation of a semi crystalline polymer such as PEO.

\section{Experimental}

Several samples of poly(ethylene oxide) were used. The samples with a molecular weight lower than $10^{4} \mathrm{~g} \cdot \mathrm{mol}^{-1}$ are usually named PEG (poly(ethylene glycol) whereas those with higher Mn were called PEO (poly(ethylene oxide). PEGs and PEOs were supplied by Scientific Polymer Products. Table 1 gives their molecular weights. 


\begin{tabular}{|c|c|c|c|c|c|c|c|c|}
\hline Sample & PE01 & PEO2 & PEG1 & PEG2 & PEG3 & PEG4 & PEG5 & PEG6 \\
\hline Mn (g.mol & $4 \times 10^{6}$ & $10^{5}$ & $10^{4}$ & $8 \times 10^{3}$ & $4.6 \times 10^{3}$ & $2 \times 10^{3}$ & $1.5 \times 10^{0}$ & $4 \times 10^{2}$ \\
\hline
\end{tabular}

Table 1: Molecular weights of the PEGs and PEOs used samples

A Mettler Toledo DSC822 ${ }^{\mathrm{e}}$ apparatus, equipped with an Intracooler and a liquid nitrogen cooling set, was used. It allows working between $500^{\circ} \mathrm{C}$ and $-150^{\circ} \mathrm{C}$ with a scanning temperature rate from $0.1^{\circ} \mathrm{C} / \mathrm{h}$ to $50^{\circ} \mathrm{C} / \mathrm{min}$. Indium $\left(156.61^{\circ} \mathrm{C}\right)$, zinc $\left(419.58^{\circ} \mathrm{C}\right)$ and heptane $\left(-90.61^{\circ} \mathrm{C}\right)$ were used to calibrate this apparatus. A Hamamatsu light generator equipped with a "Lightningcure LC6" source $(\mathrm{Xe} / \mathrm{Hg}$, "medium pressure") was affixed to the DSC device as represented on figure 1.

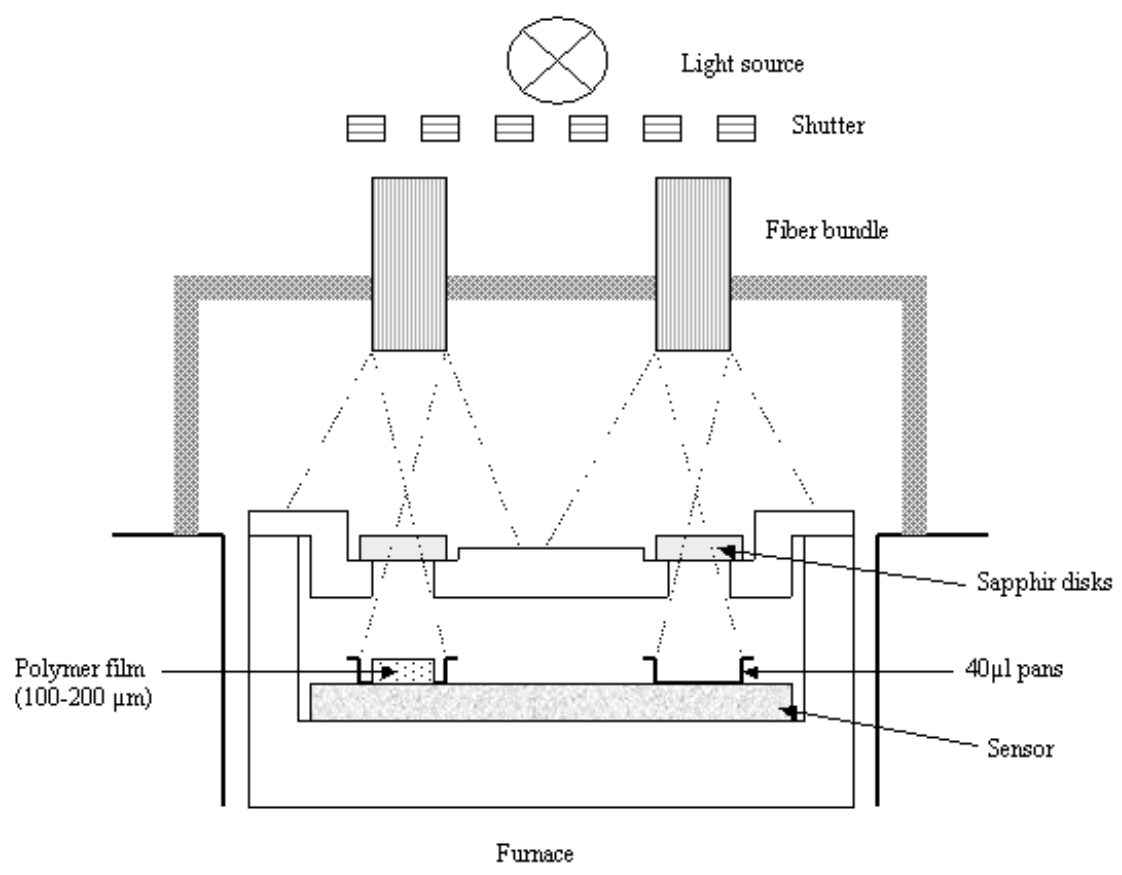

Figure 1

Principle of the photo-DSC device 
The light generator is servo-controlled by the DSC software (STARe) which permits a choice of both the light intensity from 0 to $324 \mathrm{~mW} / \mathrm{cm}^{2}$ and the duration of the irradiation. Two identical fiber bundles supply the irradiation light both to sample and reference DSC pans. The source, filtered by the sapphire disks, delivers radiations of wavelengths longer than $300 \mathrm{~nm}$, representative of outdoor ageing .

All the experiments were performed under flowing air atmosphere $\left(50 \mathrm{ml} \cdot \mathrm{min}^{-1}\right)$.

X-Ray Diffraction (XRD) was performed on a Siemens D5000 Diffractometer working in the Bragg-Brentano configuration with $\mathrm{Cu}-\mathrm{K}_{\alpha}$ radiation $(\lambda=1.5406 \delta)$. The use of a well defined sample holder allowed reproducible quantitative measurements while keeping a constant analyzed volume for all samples.

Rheological measurements were carried out at $90^{\circ} \mathrm{C}$ in isothermal conditions under air, by using an ARES rheometer (Rheometrics). Parallel plates with a diameter of 8 $\mathrm{mm}$ were used. A gap of $0.5 \mathrm{~mm}$ was adjusted between the plates. Storage modulus $\left(G^{\prime}\right)$ and loss modulus (G") were recorded in oscillatory mode as a function of time for a $2 \%$ strain and a frequency of 3 rad. $\mathrm{s}^{-1}$.

Films were prepared by pressure molding at $100^{\circ} \mathrm{C}$ and under $19 \mathrm{Mpa}$ for 1 minute between two Teflon sheets, and were analyzed by infrared spectrometry with a Nicolet 760-FTIR spectrometer, working with OMNIC software. The spectra were recorded using 32 scan summations and a $4 \mathrm{~cm}^{-1}$ resolution.

\section{Results}

1- Relationship between the crystallinity of the PEG and PEO samples and their molecular weight.

To establish the relationship between the crystallinity of the PEG and PEO samples and their molecular weight, DSC and XRD experiments were performed and compared. Figure 2 shows the results of DSC recordings. For each sample $10 \mathrm{mg}$ were submitted to an appropriate program temperature to record the corresponding endotherm of fusion. The heating rate was taken equal to $2^{\circ} \mathrm{C} / \mathrm{min}$. Both the heat of fusion $\left(\Delta \mathrm{H}\right.$ in $\left.\mathrm{J}^{-1} \mathrm{~g}^{-1}\right)$, derived from the area under the peak, and the melting temperature $(\mathrm{Tm})$, taken at the top of the signal, depend on the sample molecular weight (Mn). As can be seen in the inset, from $4 \times 10^{6}$ to $10^{4}$ g.mol ${ }^{-1} \Delta \mathrm{H}$ increases 
whereas Tm remains quite constant. From $10^{4}$ to $4 \times 10^{2} \mathrm{~g} \cdot \mathrm{mol}^{-1}$ both $\Delta \mathrm{H}$ and Tm decrease continuously.

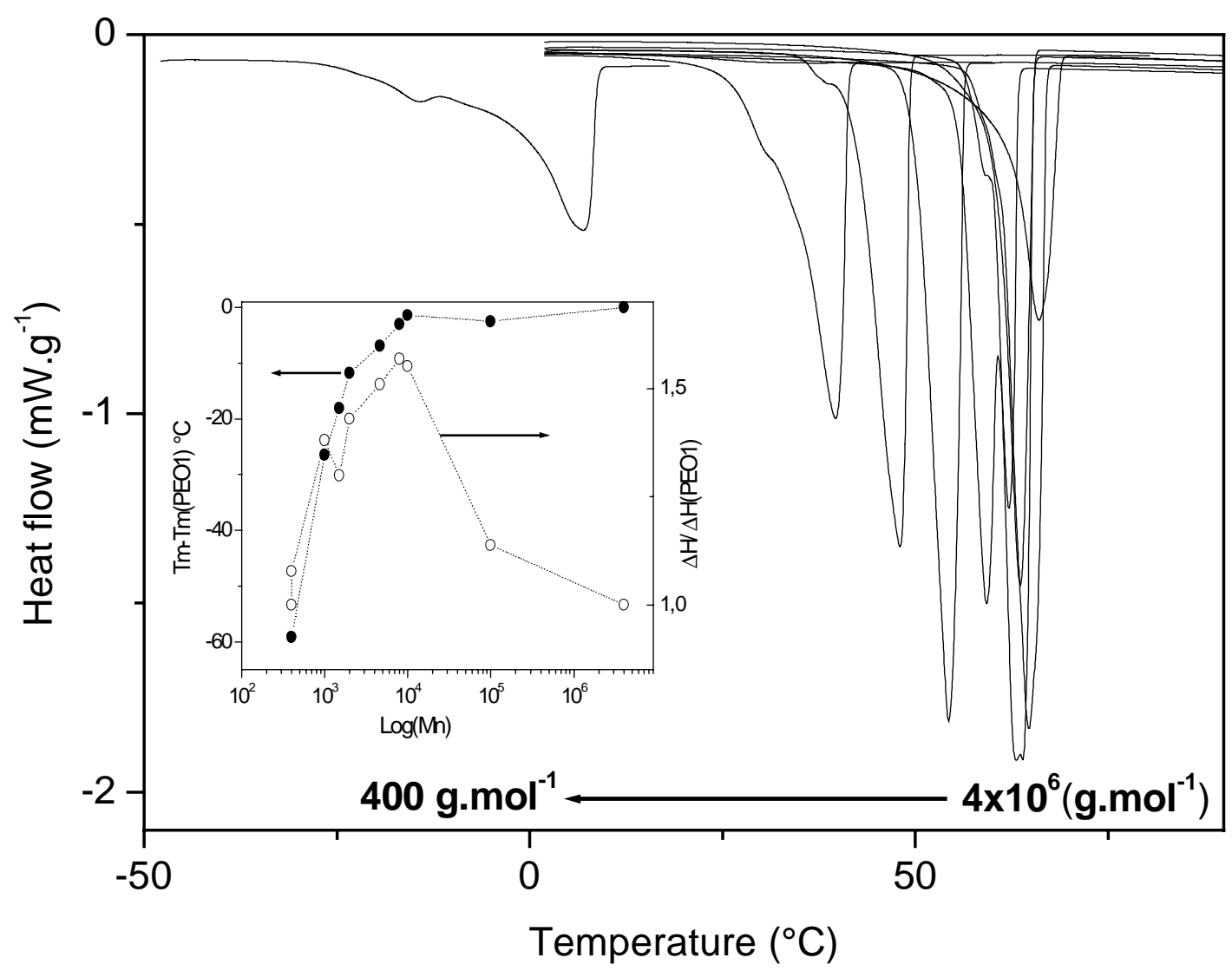

Figure 2

Endotherms of the fusion of PEGs and PEOs samples recorded at $2^{\circ} \mathrm{C} / \mathrm{min}$. In the inset are plotted (empty symbols) the ratio of the heat of fusion of each sample to the heat of fusion of the higher molecular weight sample (PEO1). The full symbols represent the evolution of the shift of melting temperature (Tm-Tm(PEO1)) as a function of molecular weight.

XRD patterns of the same samples are presented in Figure 3. The peak around $24^{\circ}$ is a combination of the (112) and (032) reflections and the peak at $20^{\circ}$ corresponds to the $(120)$ reflection $[11,12]$. The inset (a) presents an enlargement of the $(120)$ peaks. In the inset (b) the intensity of the (120) peaks was plotted versus the 
logarithm of Mn. Also, in the same inset (b), the inter-reticular distance (d) of the (120) plane was represented as function of $\log (\mathrm{Mn})$.

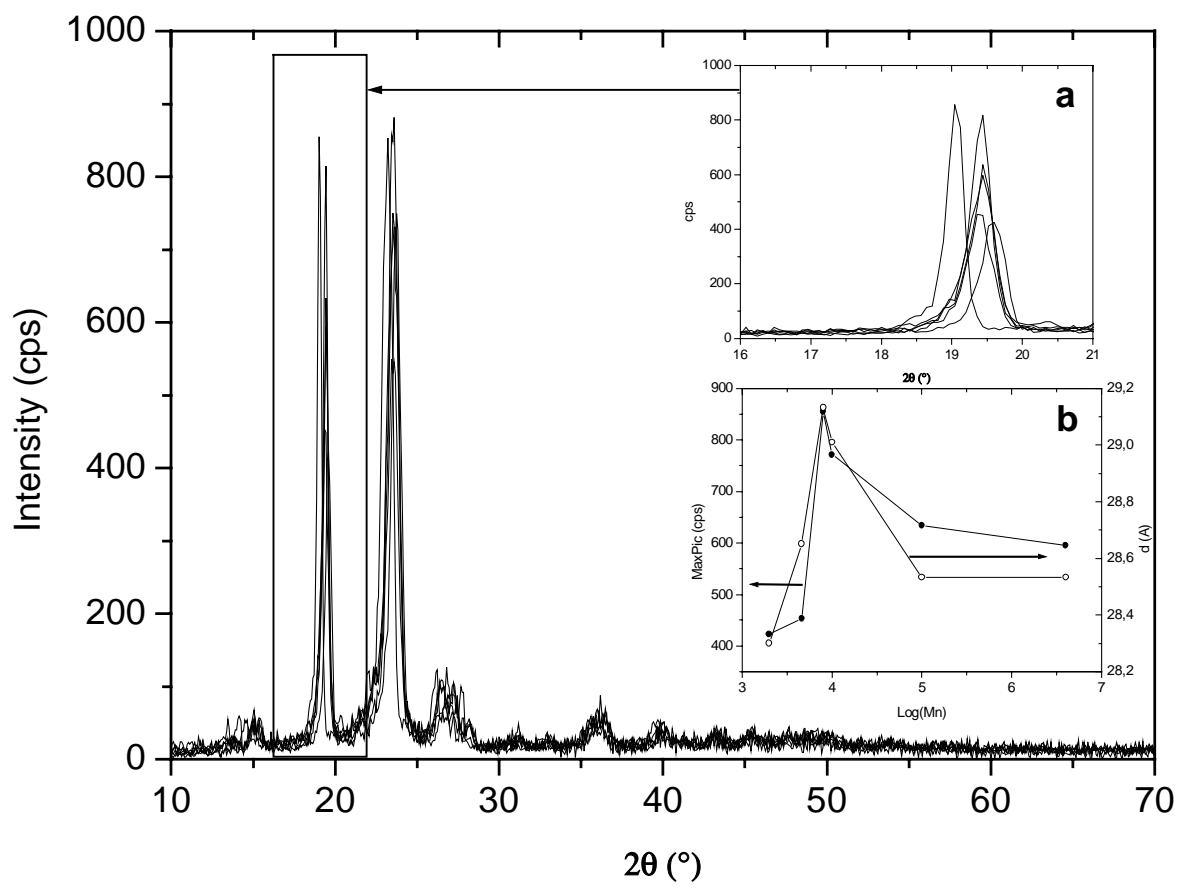

Figure 3

XRD patterns of PEGs and PEOs samples. Only the samples solid at room temperature were studied. Inset (a) is a zooming of the (120) peak. In the inset (b), the (120) peak intensity and the inter-reticular distance (d) were plotted versus molecular weights.

The intensity of the (120) reflection is obviously directly correlated with the level of crystallinity of the samples. It is indeed very striking to note that the evolution of the crystallinity with $\mathrm{Mn}$ is not monotonous since it first increases from $4 \times 10^{2}$ to $10^{4}$ g. $\mathrm{mol}^{-1}$ and then continuously decreases for higher $\mathrm{M}_{\mathrm{n}}$. This complex behavior, which deserves further experiments to be fully explained, is indeed very well reproduced by the evolution of $\Delta \mathrm{H}$. It can be concluded by comparison of DSC and XRD data, that $\Delta \mathrm{H}$ as measured by DSC is a good indicator of the cristallinity of the PEO samples. 
Furthermore, as the chain length increases, the packing of the macromolecular chains is expected to be modified thus inducing a change of the structure of the crystalline part of the samples. These modifications are attested by the evolution of the inter-reticular distance $d$ of the (120) plane as depicted in Figure 3b. The increase of $\mathrm{d}$ with $\mathrm{Mn}$ for low $\mathrm{Mn}$ is consistent with the increase of the chain length, but for higher $\mathrm{Mn}$, the behavior is more complex indicating probably a structural rearrangement of the polymers chains. Once again it is indeed worthy to note that the complex evolution of $\mathrm{d}$ correlates very nicely with $\Delta \mathrm{H}$ and the level of cristallinity. In conclusion, $\Delta \mathrm{H}$ can be considered unambiguously as a quantitative indicator of the level of crystallinity of the PEO samples.

\section{2- Photo-ageing of PEO}

PEO1 sample $\left(4 \times 10^{6} \mathrm{~g} \cdot \mathrm{mol}^{-1}\right)$ was submitted to photo-ageing using the photoDSC system. A small quantity around $6 \mathrm{mg}$ of the PEO powder was set in the DSC pan and then exposed to the program described in Figure 4. The first stage consists in a thermal equilibration of the sample. It takes 1 minute at the chosen temperature (90 ${ }^{\circ} \mathrm{C}$ for instance for the illustrated example) in the dark. Light was then switched on for a define time (5 minutes in this example). During this time segment, photochemical modifications of the polymer occur as demonstrated by the shoulder observed five minutes after the beginning of the irradiation. The third segment allows the cooling of the sample. Switching off the light, the temperature was decreased from the isothermal ageing temperature down to $0^{\circ} \mathrm{C}$ at $-2^{\circ} \mathrm{C} \cdot \mathrm{min}^{-1}$. The crystallization peak was recorded during this stage. From $0^{\circ} \mathrm{C}$, the sample was then heated up to $90^{\circ} \mathrm{C}$ and the melting endotherm was recorded. A new cycle was then launched with an irradiation time increasing after each cycle.

Only the peak of melting will be studied in this work. Light power can be chosen from 0 up to $2000 \mathrm{~mW}$ as displayed values. Two power values will be studied here: 750

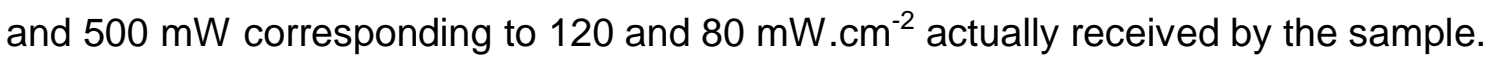
The calibration of this source has been performed and published in reference [1]. 


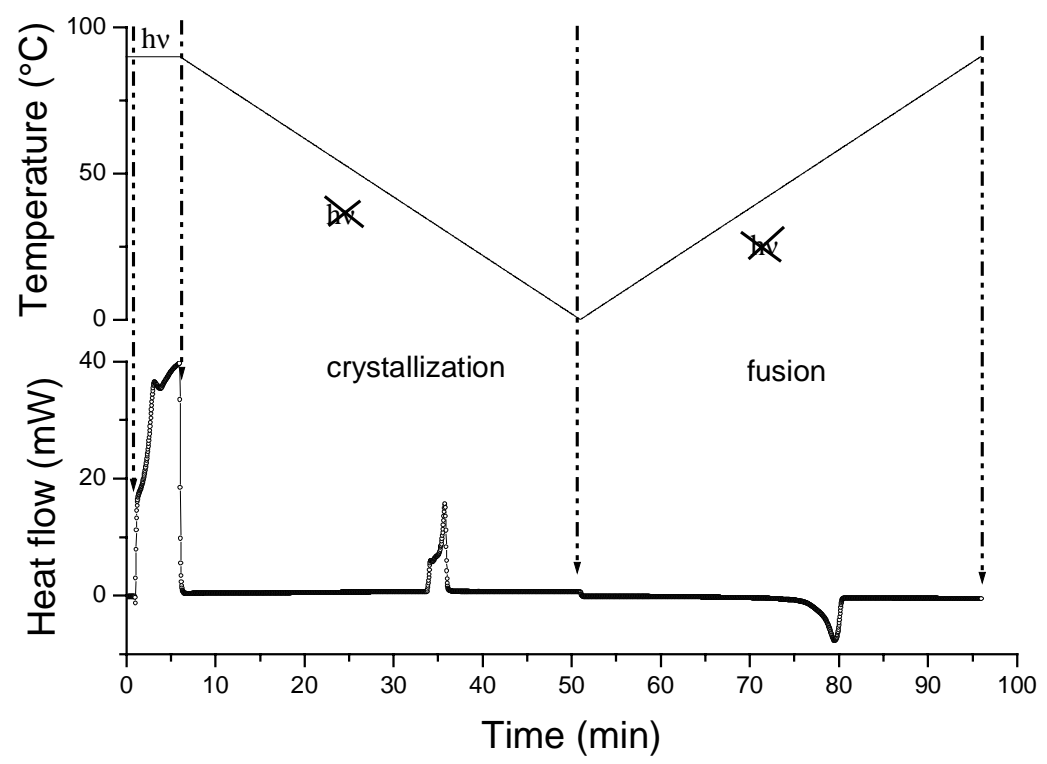

Figure 4

Temperature program used to perform photoDSC experiments. The first stage (1 $\mathrm{min}$ ) allows the completion of the sample melting. Follow the irradiation period (5 $\mathrm{min})$, the crystallization and the fusion.

Figure 5 shows typical changes in the melting endotherms of PEO photo-aged at $90^{\circ} \mathrm{C}$ under the two chosen light intensities. A regular decrease of melting temperature can be observed. Figure 6 shows the variations of the ratio $\Delta \mathrm{H}(\mathrm{t}) / \Delta \mathrm{H}(0)$ with the time of exposure to UV light at different temperatures ranging from 0 to 90 ${ }^{\circ} \mathrm{C}$. One can observe a progressive decrease of this ratio with increasing irradiation time. However it is worthy to note that, for the highest temperatures that make PEO completely or partially liquid, the ratio rapidly increases before undergoing a progressive diminution for the longer exposure time. 


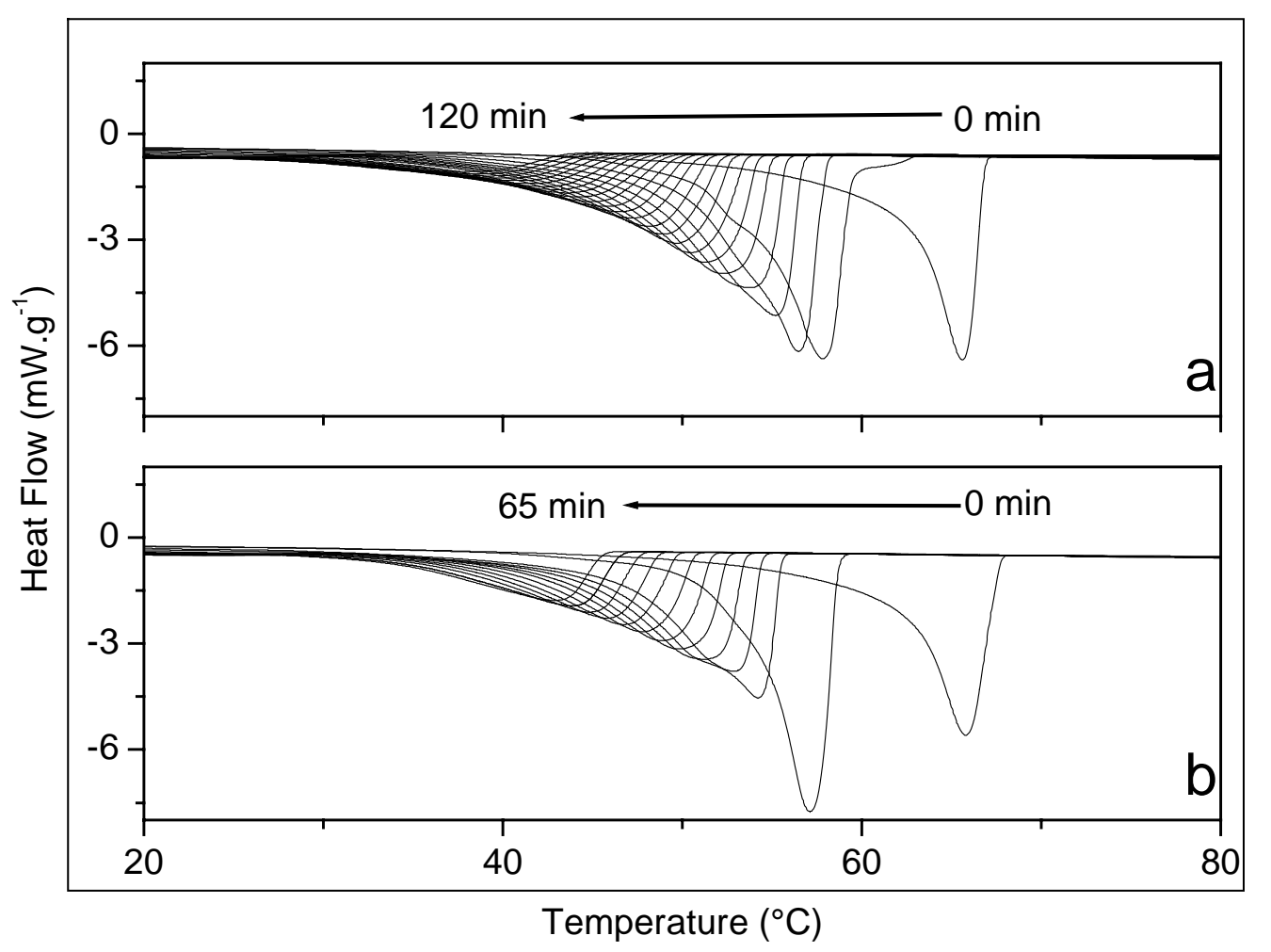

Figure 5

Thermograms of the fusion of PEO1 sample irradiated at $90^{\circ} \mathrm{C}$ and under $500 \mathrm{~mW}$ (a) and $750 \mathrm{~mW}$ (b) as displayed light intensity values. The exposure time increment was of 5 minutes and the rate of temperature change $2^{\circ} \mathrm{C} \cdot \mathrm{min}^{-1}$. 


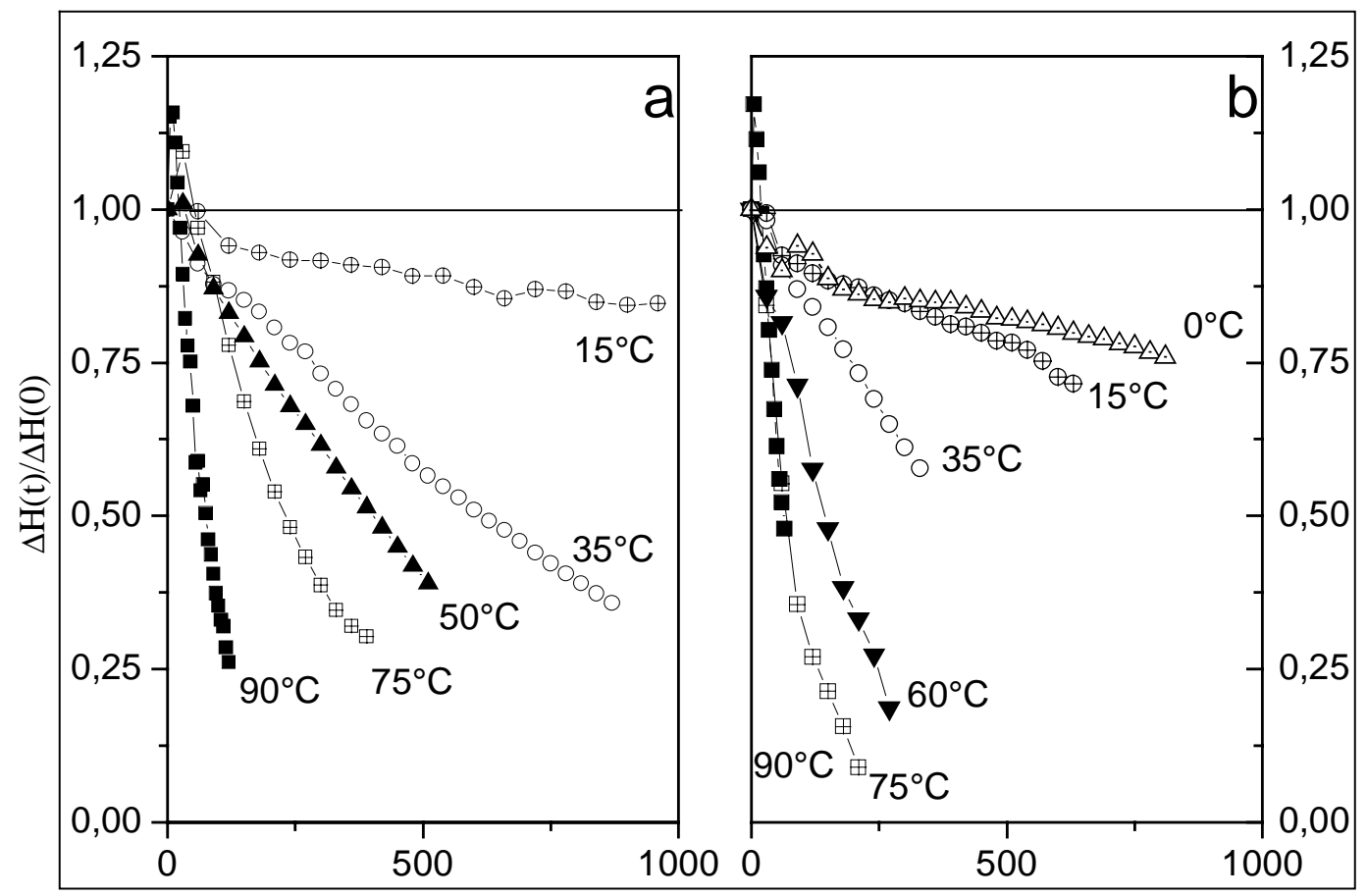

exposure time (min)

Figure 6

Evolution of the ratio $\Delta \mathrm{H}(\mathrm{t}) / \Delta \mathrm{H}(0)$ versus exposure time for PEO1 sample irradiated at various temperatures and under $500 \mathrm{~mW}$ (a) and $750 \mathrm{~mW}$ (b) as displayed light intensity values.

The evolution of $\Delta \mathrm{H}$ and $\mathrm{Tm}$ can be attributed to the decrease of the molecular weight of PEO, which suggests that chain scissions occur. This interpretation of the thermodynamic measurements is supported by the results of the IR analysis carried out at various exposure times (Figure 7). For these experiments, the ageing temperature was $75^{\circ} \mathrm{C}$ and the light intensity was $750 \mathrm{~mW}$. According to [9] the absorption band with a maximum at $1725 \mathrm{~cm}^{-1}$ and the shoulder around $1750 \mathrm{~cm}^{-1}$ were attributed to the formation of formate and ester respectively. The formation of formate end groups gives evidence of chain scissions. 


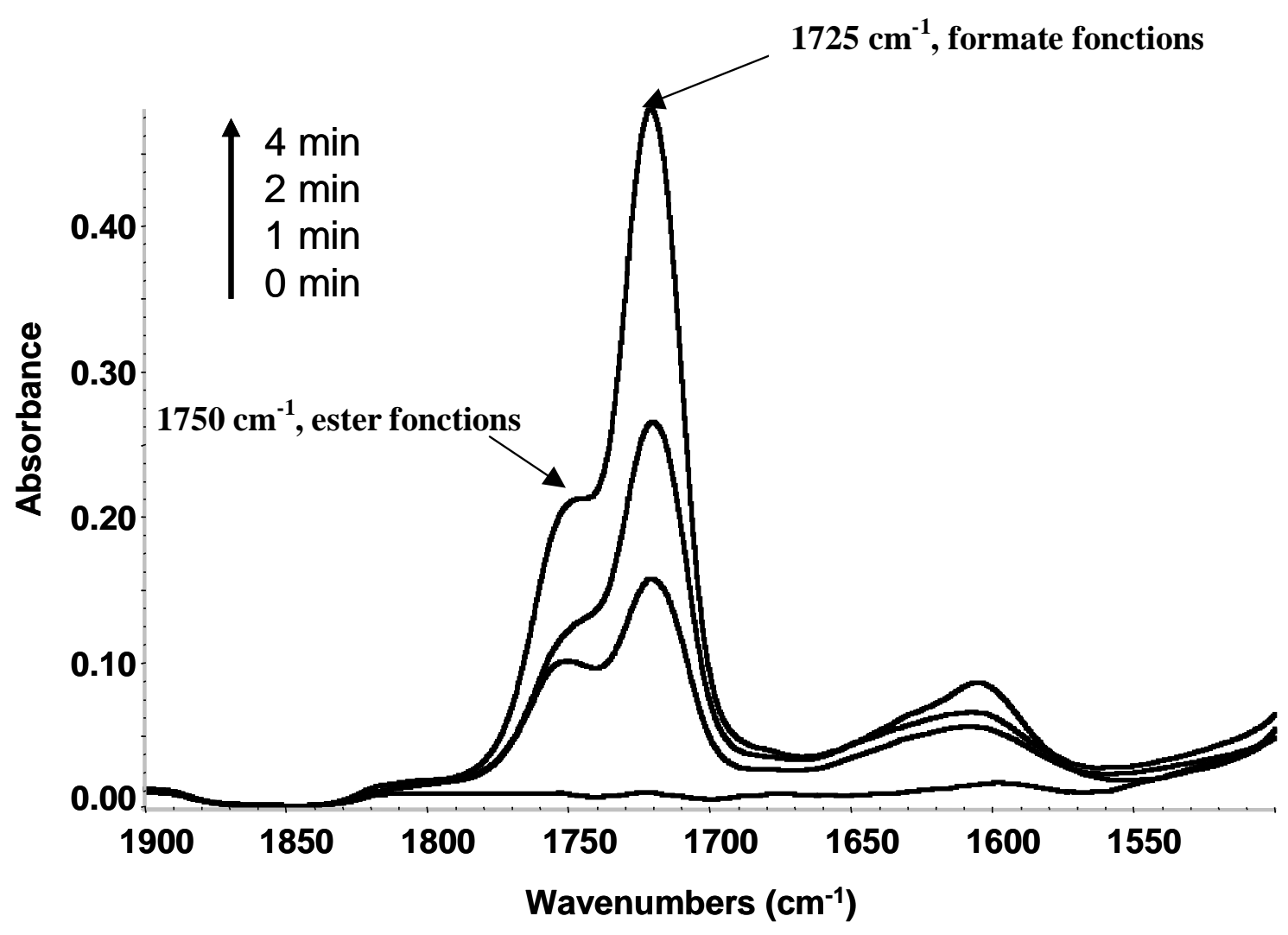

Figure 7

Carbonyl region of photo-aged PEO samples irradiated at $750 \mathrm{~mW}$ and $75^{\circ} \mathrm{C}$ for various time (0,1,2 and 4 minutes). The main band at $1725 \mathrm{~cm}^{-1}$ is attributed to formate functions whereas the shoulder at $1750 \mathrm{~cm}^{-1}$ is assigned to esters [9].

3- Thermoageing of PEO

Thermal ageing experiments were performed by using the same temperature program as shown above in Figure 4 except that light was switched off. Figure 8 shows the endotherms for the material aged at $90^{\circ} \mathrm{C}, 75^{\circ} \mathrm{C}$ and $50^{\circ} \mathrm{C}$. The evolutions that are observed are more complex. Indeed, two peaks can be pointed out at $62^{\circ} \mathrm{C}$ and $67^{\circ} \mathrm{C}$ respectively. While thermooxidation proceeds, the peak at $67^{\circ} \mathrm{C}$ progressively decreases in favor of the peak at $62^{\circ} \mathrm{C}$ before the later shifts towards the low temperatures. However, as shown in the insets (Figure 8), the ratio of the heat of melting $(\Delta \mathrm{H}(\mathrm{t}))$ to its initial value $(\Delta \mathrm{H}(0))$ reveals the same profile as recorded 
in the case of photoageing experiments. The only difference is the time scale necessary to produce comparable modifications, which is at least 10 times higher than in the presence of UV light.
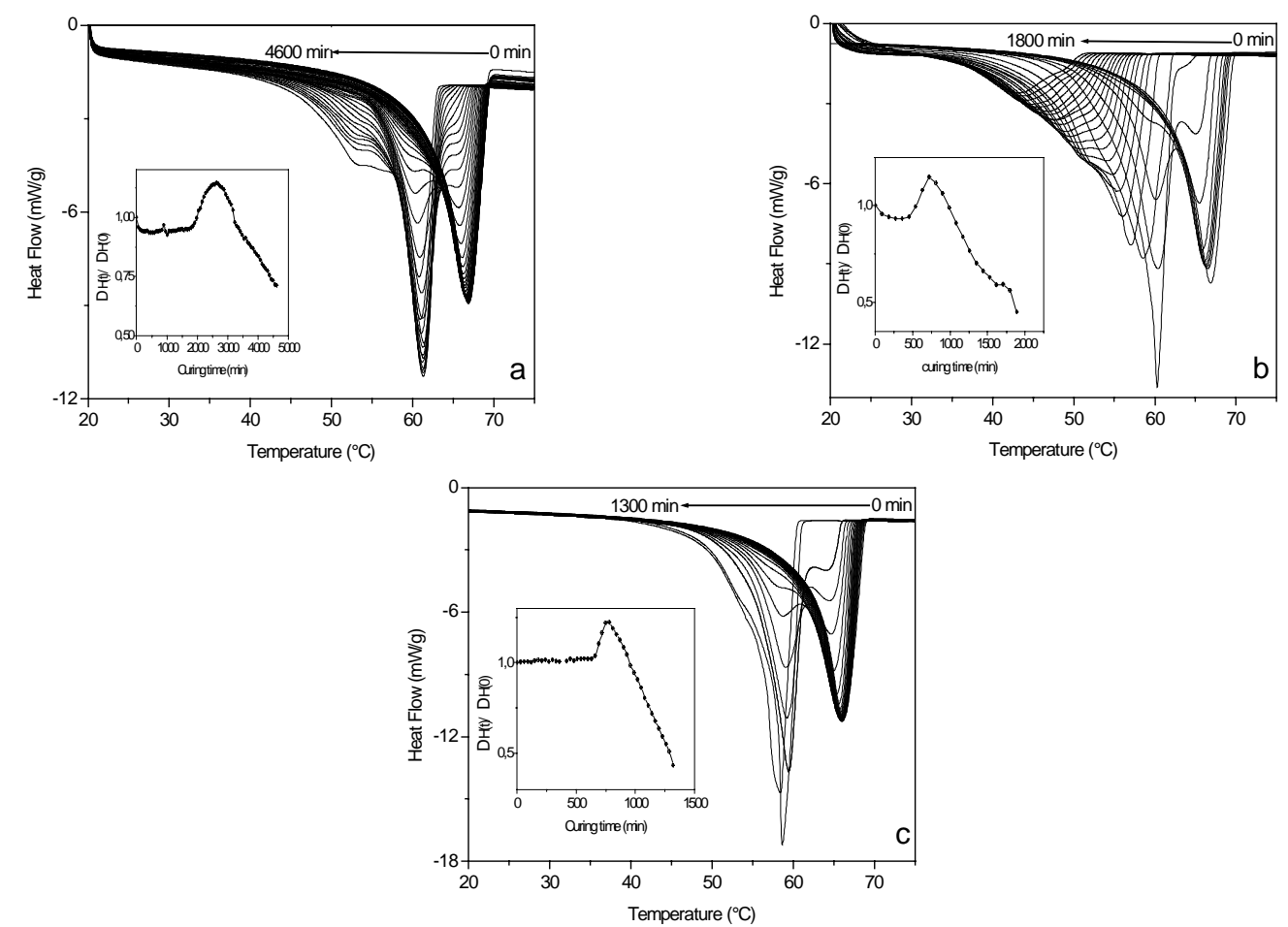

Figure 8

Thermooxidation of PEO1 at $50^{\circ} \mathrm{C}(\mathrm{a}), 75^{\circ} \mathrm{C}$ (b) and $90^{\circ} \mathrm{C}$ (c). The plots represent the successive DSC endotherms of the fusion of the material. Insets show the evolution of the ratio of $\Delta \mathrm{H}(\mathrm{t})$ to $\Delta \mathrm{H}(0)$ versus time.

To confirm the results of the thermal oxidation experiments, rheological measurements were performed.

In oscillatory measurements of polymer melt flow, the tangent of the phase angle (tan $\delta)$ has been used by many authors for characterizing the elasticity and the molecular 
structure evolution of polymer $[13,14]$. The tangent of the phase angle describes the balance between the viscous and elastic behaviors in a polymer melt:

$$
\tan \delta=G^{\prime \prime} / G^{\prime}=\eta^{\prime} / \eta^{\prime \prime} \quad \text { (Equation 1) }
$$

Figure 9 shows the evolution of the elastic modulus (G'), the viscous modulus (G") and $\tan \delta$ versus the heating time at $90^{\circ} \mathrm{C}$. The increase of the tan $\delta$ signal reveals a loss of elasticity as a consequence of the extend of the chain scissions process. Ferretti et al. [15] already observed the degradation under air by regarding the loss of complex viscosity of PEO as a function of the residence time in a mini mixer.

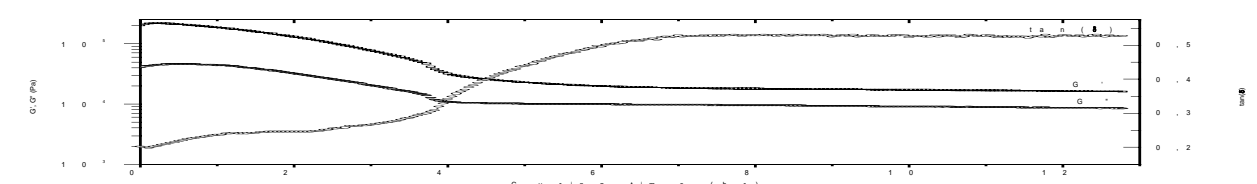

Figure 9

Evolution of the storage modulus ( $\left.G^{\prime}\right)$, the loss modulus (G") and the tangent of the phase angle (tan $\delta$ ) versus time (temperature $90^{\circ} \mathrm{C}$ ). 


\section{Discussion}

In this section, we attempt to show that the kinetic of oxidation can be followed using the photoDSC results. Combining DSC, rheology, XRD and IRTF gives direct evidences that poly(ethylene-oxide) with a high molecular weight $\left(4 \times 10^{6} \mathrm{~g} \cdot \mathrm{mol}^{-1}\right)$ undergoes chain scissions in conditions of thermo- and photooxidation. The heat of fusion measured by DSC can be chosen as the valuable parameter related to the chain scissions. As exposed in Figure 2, $\Delta \mathrm{H}$ increases until the molecular weight reaches 10000-8000 g.mol ${ }^{-1}$ and then decreases continuously. The diminution of $\Delta \mathrm{H}$ can then be considered as an indicator of the diminution of molecular size from these Mn values.

Figure 10 shows the plot of $\mathrm{Ln}(\Delta \mathrm{H}(\mathrm{t}) / \Delta \mathrm{H}(0))$ with the time of oxidation in the dark or under irradiation at two different intensities. A straight line passing through zero can be observed. In these representations, the origin of time was taken at the top of $\Delta \mathrm{H}(\mathrm{t}) / \Delta \mathrm{H}(0)$ curves. The linear variations of $\mathrm{Ln}(\Delta \mathrm{H}(\mathrm{t}) / \Delta \mathrm{H}(0))$ suggest that the rate of the global chain scissions reaction follows a first order kinetic that can be characterized by the following relations:

$$
\operatorname{Ln}\left(\frac{\Delta H(t)}{\Delta H(0)}\right)=-k t \quad \text { (Equation 2) }
$$

where $k$ is the rate constant of chain scission and $t$ the time of exposure to the ageing conditions. Table 2 summarizes the obtained $k$ values for the three DSC experiments. 

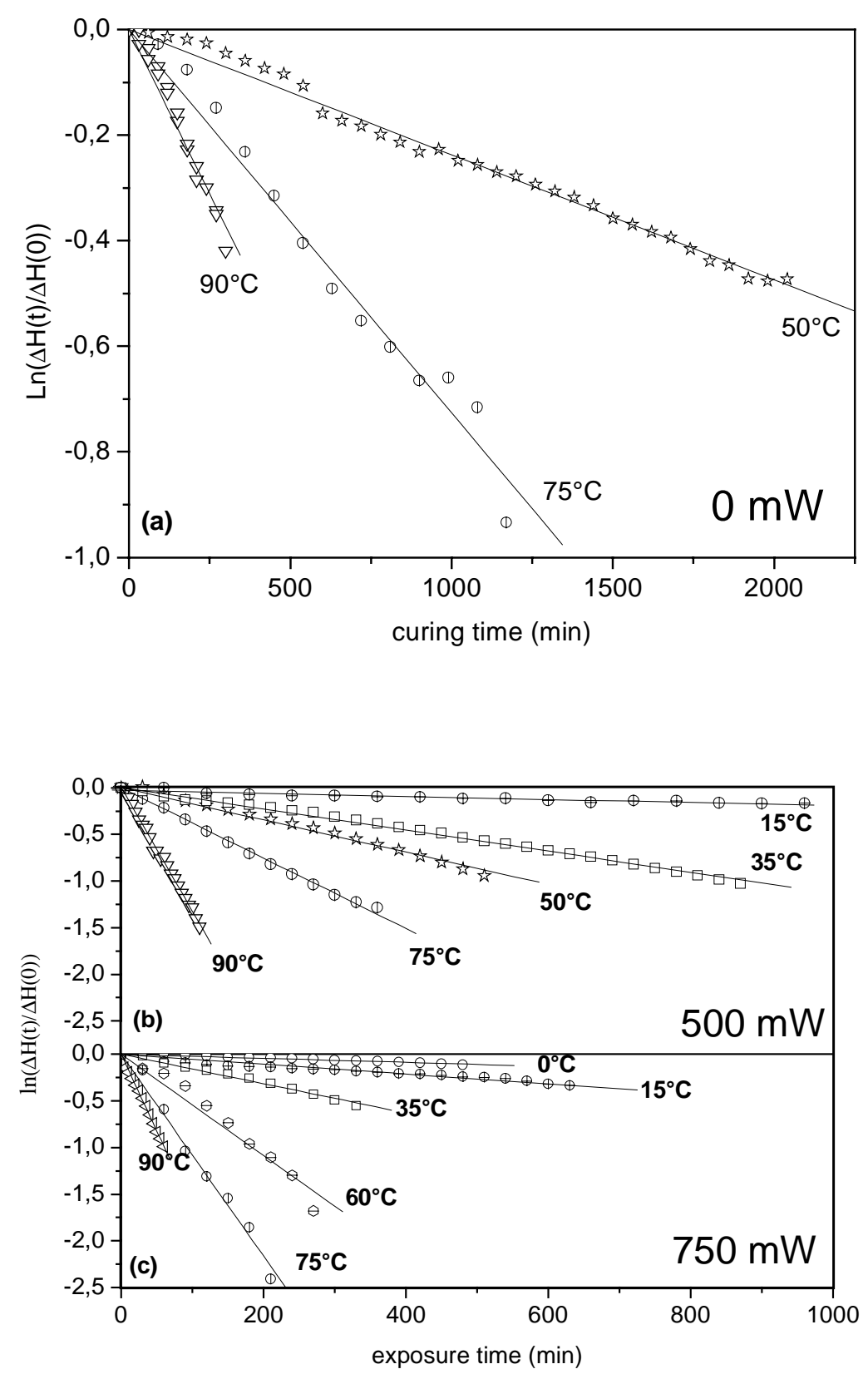

Figure 10

Kinetics of the chain scission reaction occurred in PEO1 at various temperatures. $\Delta \mathrm{H}(\mathrm{t})$ is the energy of fusion of the PEO1 after a certain irradiation or cure time ( $\mathrm{t})$. (a) : represents the thermooxidation, (b) the photooxidation with $500 \mathrm{~mW}$ and (c) with $750 \mathrm{~mW}$ as displayed light intensities which correspond to 80 and $120 \mathrm{~mW} . \mathrm{cm}^{-2}$, respectively, as actual received power irradiation. 


\begin{tabular}{|c|c|c|c|c|c|}
\hline \multicolumn{2}{|c|}{$0 \mathrm{~mW}$} & \multicolumn{2}{c|}{$500 \mathrm{~mW}$} & \multicolumn{2}{c|}{$750 \mathrm{~mW}$} \\
\hline $\mathrm{T}\left({ }^{\circ} \mathrm{C}\right)$ & $\mathrm{k}\left(\mathrm{min}^{-1}\right) .10^{4}$ & $\mathrm{~T}\left({ }^{\circ} \mathrm{C}\right)$ & $\mathrm{k}\left(\mathrm{min}^{-1}\right) .10^{4}$ & $\mathrm{~T}\left({ }^{\circ} \mathrm{C}\right)$ & $\mathrm{k}\left(\mathrm{min}^{-1}\right) .10^{4}$ \\
\hline- & - & - & - & 0 & 2 \\
\hline- & - & 15 & 2 & 15 & 5 \\
\hline- & - & 35 & 11 & 35 & 16 \\
\hline 50 & 2 & 50 & 17 & 60 & 54 \\
\hline 75 & 7 & 75 & 38 & 75 & 108 \\
\hline 90 & 12 & 90 & 132 & 90 & 731 \\
\hline
\end{tabular}

Table 2

The rate constants of chain scission occurred in PEO1 thermooxidized $(0 \mathrm{~mW})$ and photooxidized (500 and $750 \mathrm{~mW}$ ) at various temperatures.

The theory of the activated complex gives the expression of $k$ :

$$
k=\frac{k_{B} T}{h} \exp \left(-\frac{\Delta G_{\ddagger}}{R T}\right)=\frac{k_{B} T}{h} \exp \left(\frac{\Delta S_{\ddagger}}{R}\right) \exp \left(-\frac{E_{a}}{R T}\right) \quad \text { (Equation 3) }
$$

where $k_{B}$ is Boltzman's constant, $h$ Plank's constant, $\Delta G^{\neq}, \Delta S^{\neq}$and $E_{a}$ being the free enthalpy, the entropy and the energy of activation respectively and $R$ the ideal gas constant. Having performed these experiments at several temperatures, an Eyring's plot, representing $\ln \left(k h / k_{B} T\right)$ as function of the reverse of temperature $\left(T^{-1}\right)$, can be drawn. 


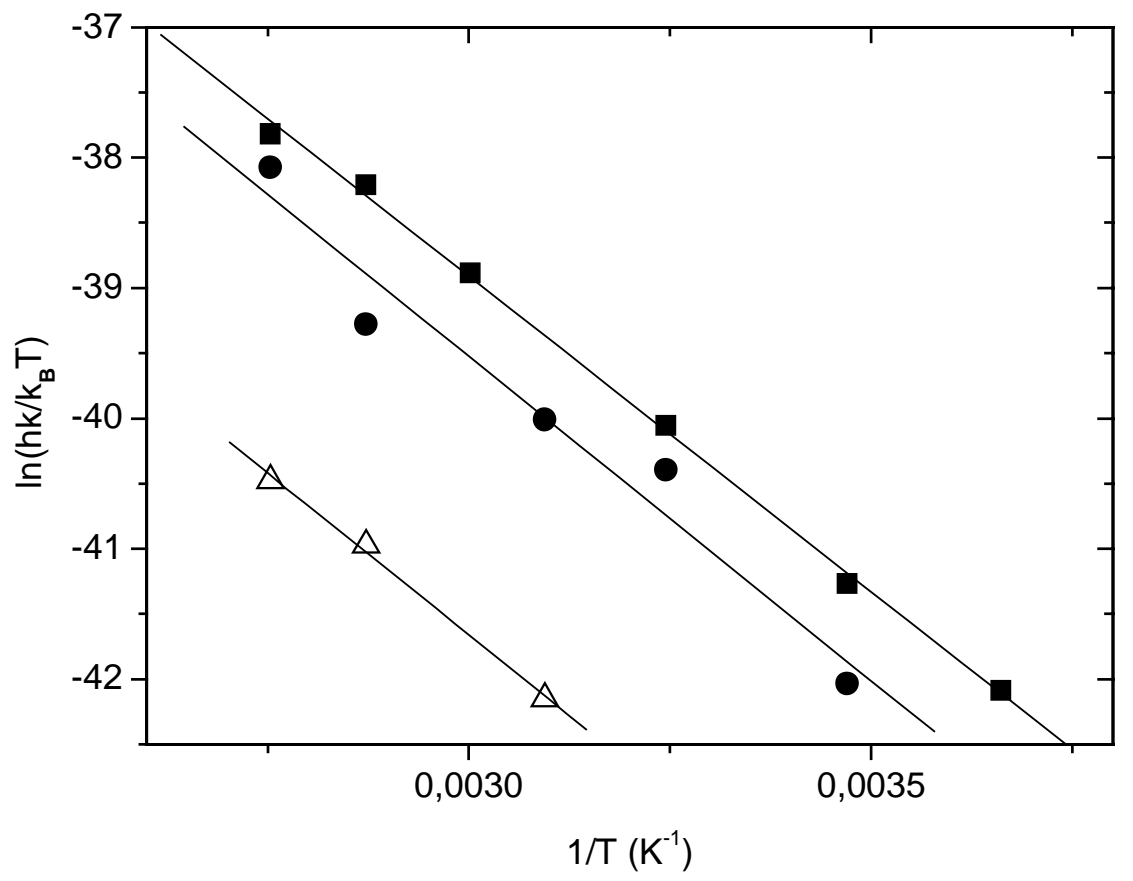

Figure 11

Eyring's plot for the photooxidation (full symbols) and the thermooxidation (empty symbols) of PEO1 $\left(4 \times 10^{6} \mathrm{~g} \cdot \mathrm{mol}^{-1}\right)$. The square full symbols correspond to a displayed irradiation intensity of $750 \mathrm{~mW}$ and the circle full symbols to $500 \mathrm{~mW}$.

Figure 11 shows a graphic representation of $\operatorname{Ln}\left(k h / k_{B} T\right)$ as a function of $1 / T$. The slopes of these straight lines represent $-E_{a} / R$ whereas their origin ordinates equal $\Delta S^{\neq} / R$. For the thermooxidation $(0 \mathrm{~mW})$ and the photooxidation experiments (500 and $750 \mathrm{~mW}$ ), the derived values of $\Delta \mathrm{S}^{\neq}$and $\mathrm{E}_{\mathrm{a}}$ are listed in Table 3.

\begin{tabular}{|l|l|l|}
\hline Intensity (mW) & $\Delta \mathrm{S}^{ \pm}\left(\mathrm{J} \cdot \mathrm{K}^{-1} \cdot \mathrm{mol}^{-1}\right)$ & $\mathrm{E}_{\mathrm{a}}\left(\mathrm{kJ} \cdot \mathrm{mol}^{-1}\right)$ \\
\hline 0 & -222 & 41.3 \\
500 & -204 & 41.4 \\
750 & -203 & 40.4 \\
\hline
\end{tabular}

Table 3: Activation energy and entropy of the photo and thermooxidation of PEO1 $\left(4 \times 10^{6} \mathrm{~g} \cdot \mathrm{mol}^{-1}\right)$. 
The photoDSC experiments indicate that the macromolecular chain scission reaction follows a first order kinetic law. The photooxidation rate constant was found several times higher than that of thermooxidation. This confirms former results that indicated that the ratio of the amounts of esters and formates were depending on the experimental conditions of ageing, e.g. thermooxidation vs photooxidation of PEO [9]. It has been shown that photooxidation generated five times more formates than esters whereas thermooxidation gave a 1/1 ratio. The mechanism given in scheme 1 [9] recalls that formates are formed with chain scission whereas the formation of esters does not involve the cleavage of the macromolecular backbone.

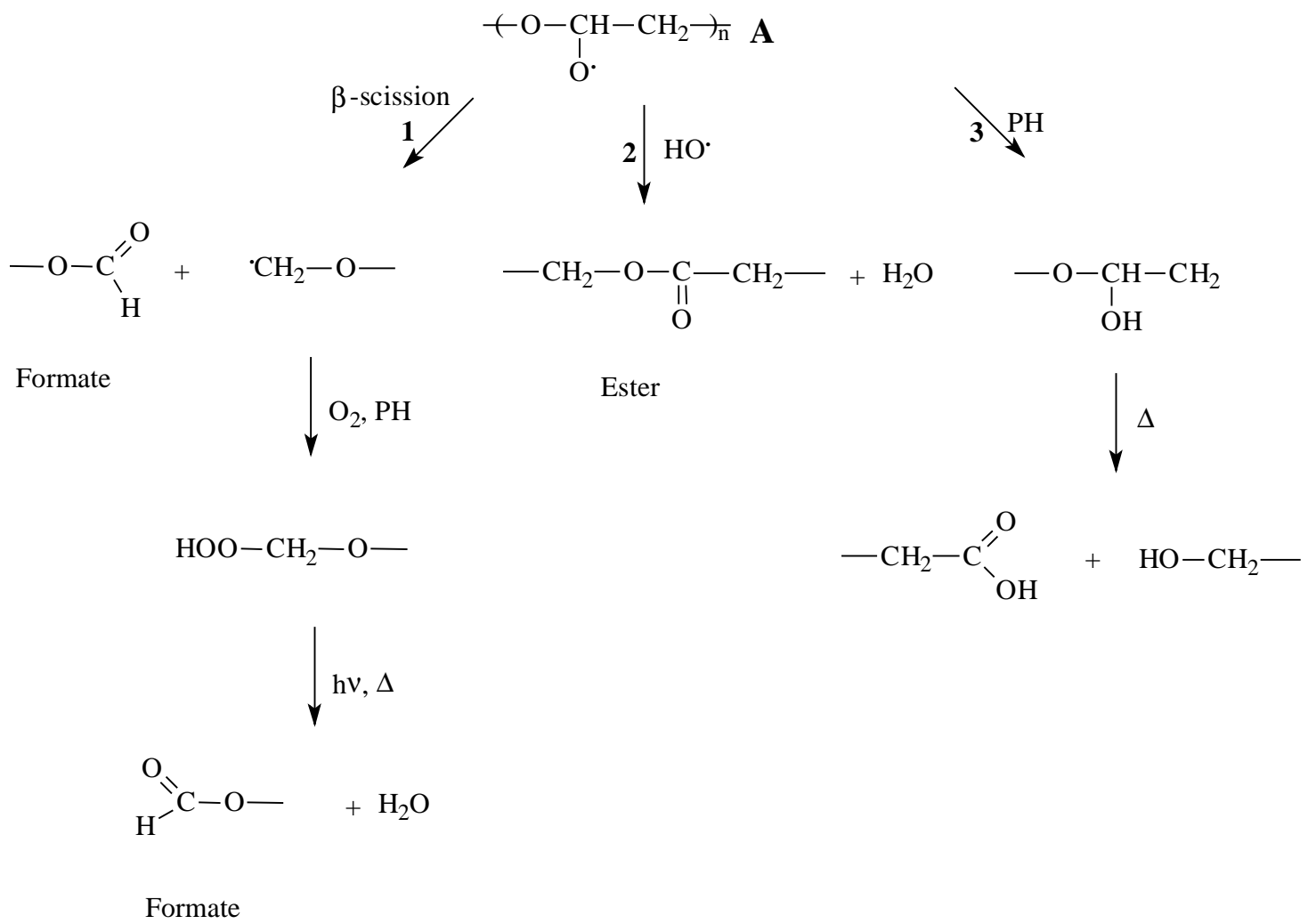

Scheme 1 
Beside, the activation energies, calculated for both thermal and photooxidation, were found quite identical. The difference in the rate constant values was attributed to the difference in the activation entropies (see Table 3). According to scheme 1, two kind of chemical bond can be cleaved, the $\mathrm{C}-\mathrm{C}$ and the O-O. Scission of the macromolecular chain involves only the homolysis of $\mathrm{C}-\mathrm{C}$ bonds. However, the cleavage of the $\mathrm{C}-\mathrm{C}$ bond is resulting from the $\beta$-scission of the alkoxy radical $\mathbf{A}$. This radical results from the decomposition of a hydroperoxide or a tetroxyde intermediates [16].
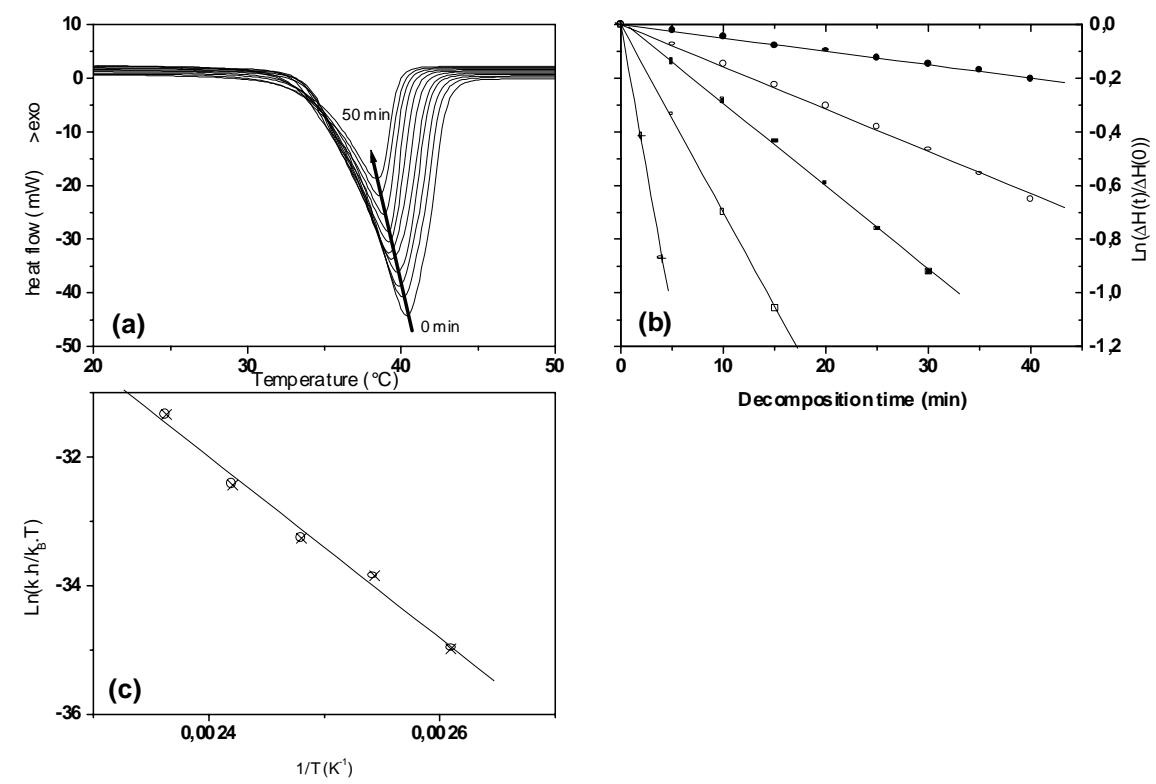

Figure 12

Kinetics of decomposition of dicumyl peroxide followed by DSC. (a): successive endotherms of the fusion. After each fusion, the sample was heated for 5 minutes at $120^{\circ} \mathrm{C}$. The same experiment was performed at $110,120,130,140$ and $150^{\circ} \mathrm{C}$. (b): $\mathrm{Ln}(\Delta \mathrm{H}(\mathrm{t}) / \Delta \mathrm{H}(0))$ vs $1 / \mathrm{T}$ plotted for the various temperatures. The slops of these plots give the rate of the decomposition reaction. (c): Eyring's plots. The slopes of theses straight lines give the activation energies.

The first order kinetic law which is deduced from the experiments reported in the paper might be attributed to the cleavage of $\mathrm{O}-\mathrm{O}$ bounds. In order to verify this assumption, the kinetics of decomposition of dicumyl peroxide (DCP) were 
determined. Figure 12 gives details of the experiments that were carried out. A DCP sample $(6 \mathrm{mg})$ was maintained at a chosen decomposition temperature $(110,120$, 130,140 and $150^{\circ} \mathrm{C}$ ) for $5 \mathrm{~min}$ under air atmosphere. After this time decomposition the sample was quickly cooled $\left(-20^{\circ} \mathrm{C} / \mathrm{min}\right)$ down to $0^{\circ} \mathrm{C}$ and then heated up to the decomposition temperature in order to record the endotherm of fusion $\left(\mathrm{Tm} \approx 40^{\circ} \mathrm{C}\right.$ ) and to start a new cycle. Figure 12 (a) shows the results of these experiments performed at $120^{\circ} \mathrm{C}$. The fusion endotherms decrease regularly with the increase of the decomposition time. The area of the fusion endotherm, representing the energy of melting $(\Delta \mathrm{H})$ is proportional to the amount DCP that has not reacted.

$\mathrm{Ln}(\Delta \mathrm{H}(\mathrm{t}) / \Delta \mathrm{H}(0))$ varies linearly with the decomposition time (t) (Figure 12, (b)) revealing that the kinetics of decomposition of DCP follows a first order law. This permits determining the rate constants that are given in table 4. Using the results summarized in this table, the Eyring's plots can be drawn as represented in Figure 12 (c).

The activation energy of DCP decomposition that can be deduced was found equal to $117 \mathrm{~kJ} / \mathrm{mol}$. This result is in a good agreement with the published activation energy values for such peroxide structures [17].

\begin{tabular}{|c|c|}
\hline $\mathrm{T}\left({ }^{\circ} \mathrm{C}\right)$ & $\mathrm{K}\left(\mathrm{min}^{-1}\right) \cdot 10^{4}$ \\
\hline 110 & 49.8 \\
120 & 157.5 \\
130 & 301.4 \\
140 & 700.2 \\
150 & 2157.0 \\
\hline
\end{tabular}

Table 4: Constants of the decomposition rate of DCP at various temperatures.

Activation energies accounting for the decomposition of peroxidic structures have been obtained and published for various macromolecular peroxides. The values range between 120 and $160 \mathrm{~kJ} / \mathrm{mol}$ [18]. 
The activation energies determined in the present study $\left(41 \mathrm{~kJ} \cdot \mathrm{mol}^{-1}\right)$ are too low to fit these reactions of decomposition. However no general and convincing explanation can be proposed. Additional experiments planned in our group are necessary, with the objective of elucidating the role of the diffusion processes, for instance.

\section{Conclusion}

The main objective of this work was to demonstrate that photoDSC is suitable to study the oxidative behavior of semicrystalline polymers. The photoDSC apparatus was used to study photooxidation and thermooxidation of a high molecular weight poly(ethylene oxide) (PEO). The changes in the enthalpy of fusion of PEO were used as an experimental parameter that is related to the length of the macromolecular chains. IR and rheological measurements have been performed to confirm that the modifications resulting from photo and thermal ageing produced in situ in the DSC equipment revealed the chain scission phenomena. It was found that the chain scission reactions undergone by PEO follow a first order kinetic law. The activation energies for both thermo and photooxidation reactions were found identical and equal to $41 \mathrm{~kJ} / \mathrm{mol}$. The activation energy for cleavage of the -O-O- bond in dicumyl peroxide was measured and estimated as $117 \mathrm{~kJ} / \mathrm{mol}$. This suggests that the cleavage of the alkoxy peroxide which is involved in the commonly proposed reaction mechanism could not be the determining stage in the global kinetics of chain scissions.

\section{References}

1- M. Morel, J. Lacoste and M. Baba M. Polymer, 46(2005) 9274-9282.

2- Yeong-Tarng Shieh, Gin-Lung Lui, Kuo Chu Hwang Chia-Chun Chen, Polymer 46(2005)10945-10951.

3- L. Sun, L. Zhu, Q. Ge, R.P. Quirk, C. Xue, S.Z.D. Cheng, B.S. Hsiao, C.A. Avila-Orta, I.Sics, M.E. Cantino. Polymer 45(2004)2931-2939.

4- V.M. DA COSTA, T.G. FISKE and L.B. COLEMAN. J. Chem. Phys., 101 (4) (1994) 2746-2751.

5- Tatsuo MIYAZAWA, Kunio FUKUSHIMA and Yoshiko IDEGUCHI. J. Chem. Phys., $\underline{37}$ (12) (1962)2764-2776. 
6- A. O. PORTO, G. GOULART SILVA and W.F. MAGALHAES. J. Polym. Sci., part B, 37 (1999) 219-226.

7- Harris JM. Poly(ethylene glycol) chemistry: biotechnical an biomedical application. New York: Plenum Press; 1992.

8- Blin J-L, Léonard A, Yuan Z-Y, Gigot L, Vantomme A, Cheetham AK, et al. Angew Chem Int Ed 2003;42:2872.

9- S Morlat, J-L Gardette, Polymer, 42 (2004) 6071-6079.

10-Wilhem C, Gardette JL, Polymer 1998;39:5973-80.

11-Douwe Homming, Bart Goderis, Igor Dolbnya, Harry Reynaers, Gabriel Groeninckx, Polymer xx (2005) in press.

12-Brotel E, Hodorowicz S, Lamot R, Makromol Cem 1979;180:2491-8.

13- Young Jun Lee, Ho Sang Sohn and Seung Ho Park, Korea-Australia Rheology Journal, Vol.12, N.3/4, December 2000 pp. 181-186

14- A. Kumar, S. Commereuc, V. Verney, Polymer Degradation and Stability, 85 (2004), 751-757.

15- Antonio Ferretti, Pierre J. Carreau, Pierre Gerard, Polymer Engineering and Science, Vol. 45 (2005), Issue 10, pp $1385-1394$.

16- Phillipart J.L., Gardette J.L., Polymer Degradation and Stability, 71 (2001), 189-194

17- Gugumus Polymer Degradation and Stability 69 (2000) 23-34.

18- De P., Chattopadhyay S., Madras G., Sathyanarayana D.N. Journal of Applied Polymer Science Vol. 86, 957-961 (2002). 